\title{
TEMPORALIDADE E ESPACIALIDADE NA ESTRUTURA DO SELF NAS ABORDAGENS SEMIÓTICA E DIALÓGICA
}

\author{
Mariane Lima de Souza* \\ William B. Gomes ${ }^{\#}$
}

\begin{abstract}
RESUMO. O artigo apresenta uma análise comparativa e crítica de duas abordagens comunicacionais do fenômeno self: a teoria dialógica e a teoria semiótica. Argumenta-se que as diferenças de ênfase na dimensão espaçotemporal do self em cada teoria implicam duas epistemologias e ontologias distintas. As duas perspectivas trabalham com o signo, que é a percepção de sentido conversacional (ou dialógica) e a funcionalidade (ou pragmática) da expressão. A perspectiva semiótica volta-se para a funcionalidade do fenômeno e recorta um contexto de pesquisa inserido na psicologia dos processos básicos, apoiando-se em uma ontologia evolucionária do self como gerador de signos. A perspectiva dialógica volta-se para a aplicabilidade do conceito e recorta um contexto de pesquisa aplicada direcionada para a psicologia clínica e para as relações interpessoais, apoiando-se em uma ontologia metafórica e romântica e mais preocupada com o diálogo entre as posições do self.
\end{abstract}

Palavras-chave: Self semiótico; self dialógico; temporalidade.

\section{TEMPORALITY AND SPATIALITY IN THE STRUCTURE OF THE SELF IN THE SEMIOTIC AND DIALOGICAL APPROACHES}

\begin{abstract}
The main goal of this article is to introduce to a critical account of two communicative approaches on phenomenon of self: semiotic self and dialogical self theoretical frameworks. Both perspectives are analyzed separately and then compared. One argues that differences on space-temporal dimension of the self in each theory imply distinct epistemology and ontology. Although both perspectives work with the sign that is the conversational (or dialogical) perception of meaning, and the functionality (or pragmatics) of expression, different assumptions concerning the culture influences set different places for both theories. The semiotic perspective turns to the phenomenon's functionality and sets a research context embedded on psychology of basic process, supported by evolutionary ontology concerned to self as meaning creator. The dialogical perspective turns to the applicability of the concept and sets an applied research context directed towards clinical psychology and supported by metaphoric and romantic ontology concerned to dialogue among self positions.
\end{abstract}

Key words: Semiotic self; dialogical self; temporality.

\section{TEMPORALIDAD Y ESPACIALIDAD EN LA ESTRUCTURA DEL SELF EN LOS ACERCAMIENTOS SEMIÓTICO Y DIALÓGICO}

RESUMEN. El presente estudio discute los acercamientos comunicativos en el fenómeno del self: la teoría semiótica y la teoría dialógica. Ambas perspectivas se analizan por separado y después se comparan. Se argumenta que las diferencias en la dimensión espacio-temporal del self en cada teoría impliquen en epistemologías y ontologías distintas. Aunque ambas perspectivas trabajan con el signo que es la percepción del sentido conversacional (o dialógico), y la funcionalidad (o pragmática) de la expresión, asunciones diferenciadas referentes a las influencias de la cultura determinan hogares diversos para ambas teorías. La perspectiva semiótica mira a la funcionalidad del fenómeno y fija un contexto de la investigación encajado en la psicología del proceso básico, apoyada en una ontología evolucionaria del self como generador de signos. La perspectiva dialógica mira a la aplicabilidad del concepto y fija un contexto aplicado a la investigación dirigido hacia la psicología clínica, apoyada en una ontología metaforica y romántica, más preocupada con el dialogo entre las posiciones del self.

Palabras-clave: Self semiótico; self dialógico; temporalidad.

* Doutora, professora da Universidade Federal do Espírito Santo, Departamento de Psicologia Social e do Desenvolvimento.

\# Doutor, professor da Universidade Federal do Rio Grande do Sul. 
A partir da década de 1990, diversas abordagens vêm resgatando o interesse pelo fenômeno do self, não apenas no campo da psicologia, mas também na linguística, na sociologia e, até mesmo na neurobiologia ${ }^{1}$. Self é aqui definido em um sentido básico de processo reflexivo da consciência, sem o qual não poderia haver nada do que tem sido definido como associado ao termo self: conhecimento de si e do outro, identidade, autoconceito, etc. $\mathrm{Na}$ teorização psicológica, os conceitos de narratividade e dialogicidade apresentam-se como as novas temáticas que retomam a discussão do fenômeno self no contexto da comunicação (Souza \& Gomes, 2005). Como de especial relevância nesse contexto destacamse duas abordagens comunicacionais do fenômeno: a teoria do self dialógico e a do self semiótico. A perspectiva dialógica refere-se aos primeiros trabalhos de Hermans, Kempen e Van Loon (1992) e Hermans e Kempen (1993), bem como à série de estudos publicados posteriormente por Hermans (1999, 2001a, 2001b, 2002 e 2003) sobre o self, que é entendido como uma multiplicidade de vozes. A perspectiva semiótica refere-se ao trabalho de Wiley (1994) sobre o self enquanto signo, isto é, a capacidade humana universal e genérica de dar sentido às experiências de si e do mundo.

O presente trabalho, ao revisar as teorias representadas pelos professores eméritos Humbert Hermans (Universidade de Nijmagen - Holanda) e Nobert Wiley (Universidade de Berkeley - EUA), analisa e exemplifica como as elaborações semióticas e dialógicas redefiniram o conceito self em uma estrutura dialógica e multivocal. $\mathrm{O}$ foco central do artigo é a expressão consciente do self definido em sua condição processual de reflexividade, isto é, da consciência voltada sobre si mesma. Argumenta-se que as diferenças de ênfase na dimensão temporal (perspectiva semiótica) ou espacial (perspectiva dialógica) do self caracterizam duas epistemologias (métodos de investigação) e ontologias (especificações conceituais) distintas: o self como uma configuração descentralizada de posições (espaço) e o self como processo reflexivo (tempo). Essas distinções, por sua vez, levam a uma nova compreensão das noções de

1 A busca de uma tradução adequada para o termo self nas diversas línguas configura é, por si só, uma parte significativa da investigação do fenômeno (conferir Harré \& Gillett, 1999 e Toulmin, 1977). Nas publicações em língua portuguesa no Brasil, self não tem sido traduzido (conferir Damásio, 2000; Harré \& Gillett, 1999; Taylor, 1997 e Wiley, 1996). Nas traduções publicadas em Portugal, é possível encontrar o termo self como consciência (Eccles, 2000), eu (Bermúdez, 2000) e si (Damásio, 2003, versão portuguesa do próprio autor). dialogicidade ou conversação, que formam a base do arcabouço teórico do self nas duas abordagens.

O artigo está organizado em três partes. As duas primeiras dedicam-se à exposição das abordagens consideradas, destacando as origens e bases conceituais. A terceira discute as duas propostas, contrastando as dimensões de tempo e espaço como estruturas semióticas e dialógicas do self. Por fim, aponta-se para as pesquisas que estão surgindo, associadas às teorias do self dialógico e do self semiótico.

\section{O SELF DIALÓGICO E A ESPACIALIDADE DO DIÁLOGO}

O cerne da abordagem dialógica do self é a ênfase na presença de múltiplas vozes em uma narrativa espacialmente estruturada e corporificada (Hermans, 2001a, 2001b; Hermans \& Kempen, 1993). A perspectiva dialógica apresenta-se como uma teorização de epistemologia construcionista que caracteriza o self como narrador (Hermans, Kempen \& Van Loon, 1992). Para os autores, as abordagens tradicionais sobre o self refletem uma perspectiva etnocêntrica do Ocidente sobre a personalidade. A consequência é uma concepção de self unitário ou multifacetado e baseado no pressuposto de uma mente desincorporada ou racional. A alternativa do caráter racionalista e individualista das concepções psicológicas contemporâneas de self é a ênfase na capacidade imaginativa do homem e na ideia da mente humana como basicamente ativa e organizadora, indicada nos trabalhos pioneiros de Vico (1744/1999), Vaihinger (1935) e Kelly (1955).

A concepção do self em termos narrativos resulta da combinação entre o moderno movimento na ciência literária, especialmente representado de Mikhail Bakhtin (1895-1975) sobre o romance polifônico, e a abordagem narrativa em psicologia. O self dialógico é o resultado da conversação do Eu e do Mim proposta por William James (1890/1990) e revista como distinção entre Autor e Ator por Hermans, Kempen e Van Loon (1992). A revisão foi inspirada em distinções semelhantes oferecidas por Bakhtin (1929/1973) e por Sarbin (1986).

A distinção entre o Eu e o Mim como os dois principais componentes do self é tomada do trabalho clássico de James (1890/1990). O Eu representa o self como sujeito e é caracterizado como contínuo (senso de mesmidade e de persistência através do tempo), distinto (sentimento de uma existência separada dos outros) e volitivo (senso de vontade pessoal). O Eu jamesiano é capaz de apropriar-se e rejeitar ideias 
como parte de sua capacidade autorreflexiva, funcionando como uma fonte original de pensamento e produção de ideias (Hermans \& Kempen, 1993). O Mim representa o self como objeto e é caracterizado como material (corpo, roupas, propriedades), social (relações, papéis) e espiritual (pensamentos, consciência). Para Hermans e Kempen (1993), a extensão do self a esses constituintes impede o entendimento errôneo do interjogo entre o Eu e o Mim como um processo que se passa dentro do indivíduo e separadamente do processo de pensamento de outras pessoas: "na solução de James para esse problema, o self é - enquanto Eu - distinto de outras pessoas, mas - enquanto Mim social - a perspectiva do outro está incluída no self" (p. 45).

A tradução da distinção Eu-Mim em uma abordagem narrativa (Mancuso \& Sarbin, 1983; Sarbin, 1986) coloca o pronome Eu em relação ao autor e o pronome Mim em relação ao ator ou à figura narrativa. $\mathrm{O}$ self é identificado com o autor, permitindo que o Eu construa uma história na qual o Mim é o protagonista. Para Hermans e Kempen (1993), o self-autor torna-se um espaço onde o Eu observa o Mim e coordena seus movimentos em uma construção narrativa (tempo).

Essa concepção do Eu como um autor e do Mim como um ator observado expande-se na metáfora do romance polifônico (Bakhtin, 1929/1973) para dar ao self a capacidade de integrar as noções de narrativa imaginária e de diálogo. Não obstante, a metáfora do romance polifônico não implica a existência de um Eu hierarquicamente superior que organiza os constituintes do Mim, o romance polifônico enfatiza justamente a descentralização do $\mathrm{Eu}$ em uma multiplicidade de posições que funcionam como autores relativamente independentes, contando suas histórias sobre seus respectivos Mims como atores (Hermans \& Kempen, 1993).

$\mathrm{Na}$ medida em que se estabelece o diálogo entre as diferentes posições do eu, a presença simultânea de interlocutores em um mesmo ponto do eixo temporal configura uma espacialização do tempo. Essa forma de configuração na qual a noção de espaço é dada prioritariamente sobre o tempo é denominada princípio da justaposição (Bakhtin, 1929/1973). Conforme Hermans (2001b), a coalizão de duas posições em tempo e espaço determinados é introduzida por Bakhtin, com o objetivo de pontuar a conectividade de relações temporais e espaciais que estão artisticamente expressas na literatura.

Tal concepção de narrativa torna claro o papel fundamental da metáfora polifônica para a noção de self dialógico, subvertendo a ordem cronológica em termos de início, meio e fim. O papel da dimensão espacial é resgatado com base na crítica ao viés temporal das concepções de narrativa e autonarrativa em psicologia. As relações dialógicas são, então, trazidas para uma dimensão espacial, na medida em que se enfatizam a simultaneidade, a justaposição e a descontinuidade.

A unidade de ênfase na dimensão espaçotemporal do self é vista como uma conquista e não como um $a$ priori dado. Essa unidade será consequência da própria capacidade do self de se colocar em uma posição a partir da qual as outras posições, incluindo suas relações mútuas e sua organização específica, possam ser exploradas: a metaposição (Hermans, 2003). Em resumo, a metaposição é um tipo especial de posição que o Eu pode assumir e que contribui, mais do que a maioria das outras posições, para a integração e unidade do repertório do self.

Resumindo, a abordagem narrativa e a ênfase no espaço e no diálogo entre posições estão combinadas para gerar a definição de self enquanto multiplicidade de posições do Eu. As posições são relativamente autônomas, flutuantes, alternando-se em diferentes direções. Explicam Hermans, Kempen e Van Loon (1992):
$\mathrm{O}$ eu tem a capacidade de imaginariamente dotar cada posição com uma voz, de forma que relações dialógicas entre posições possam ser estabelecidas. As vozes funcionam como personagens interativos em uma história (...). Como diferentes vozes, esses personagens trocam informações sobre seus respectivos mim e seus mundos, resultando em um complexo self, estruturado de forma narrativa. (pp. 28-29).

A perspectiva dialógica do self, em oposição ao modelo de self individualista, parte da pressuposição de que o sentido de si, do outro e do mundo é constituído por uma diversidade de posições. Tal diversidade se constitui nas relações sociais que produzem o self e que são transformadas pelo próprio self. O outro, enquanto muitos outros, pode participar das posições e tomar parte nas múltiplas vozes, no sentido de que o eu pode engendrar outra pessoa como uma posição a ser ocupada, criando uma perspectiva alternativa sobre o mundo e sobre si mesmo. Conforme Hermans (2001b), assim como um compositor precisa dos instrumentos certos para expressar uma ideia musical, o self somente pode estabelecer relações com uma variedade de situações se ele é composto de uma variedade de posições. Em outros termos, a crescente complexidade de nossa 
condição social, bem como de nossa história pessoal e coletiva, exige uma concomitante complexidade do self.

\section{O SELF SEMIÓTICO E A TEMPORALIZAÇÃO DO DIÁLOGO}

A perspectiva semiótica define o self como o produto da assimilação de signos culturais (Pickering, 1999) que funciona como um processo semiótico (Wiley, 1994). A perspectiva semiótica apresenta-se como teorização resultante da síntese do pensamento de dois autores clássicos do pragmatismo americano: Charles Sanders Peirce (1839-1914) e George Herbert Mead (1863-1931). A noção de self dos pragmatistas emerge de uma tentativa de descentrar o self cartesiano. A discrepância entre os dois autores quanto à explicação do pensamento inspirou Wiley (1994) a desenvolver uma teoria trialógica do self, centrada na direção temporal do diálogo interno. No modelo de Wiley, o self funciona como um processo semiótico, que é a conversação interna.

$\mathrm{O}$ pensamento enquanto processo reflexivo direcionado do presente (Eu) para o passado (Mim) de Mead é combinado ao pensamento enquanto processo interpretativo, direcionado do presente $(\mathrm{Eu})$ para o futuro (Você) de Peirce. Tem-se, então, um processo semiótico mais abrangente, representado na conversação triádica Eu-Mim-Você. Estas três instâncias são definidas como fases temporais do self que estabelecem uma conversação interna. Não obstante, a conversação interna não é um diálogo simultâneo entre as instâncias: apenas o self presente (o Eu) pode falar, enquanto o self passado (Mim) e o self futuro (Você) apenas podem ouvir ou serem objetos da fala do Eu. O self torna-se, então, um processo constante de autointerpretação, uma vez que o self presente interpreta o self passado para o self futuro, movendo-se através da linha do tempo e tendo seu processo semiótico constantemente transformado (Wiley, 1994). A tríade Eu-Mim-Você é acoplada à tríade semiótica de Peirce signo-interpretante-objeto. A relação lógica entre signo, interpretante e objeto é definida por Peirce (1958) do seguinte modo:

Um signo esforça-se para representar um Objeto no mínimo em parte, o qual é por isso e em certo sentido a causa ou determinante de um signo, mesmo que ele represente seu Objeto falsamente. Mas dizer que o signo representa seu Objeto implica que esse signo afeta a mente e de certo modo determina nesta mente alguma coisa que é mediatamente devido ao Objeto. Essa determinação da qual a causa imediata ou determinante é o signo e da qual a causa mediata é o Objeto pode ser chamada de Interpretante. ${ }^{2}$ (CP. 6.347)

As instâncias que estabelecem a conversação interna dão ao self uma estrutura tripartida: o passadomim-objeto; o presente-eu-signo e o futuro-vocêinterpretante. Essa estrutura pode ser vista como um "container" dentro do qual estão os "conteúdos". Todavia, alerta Wiley (1994), o caráter aparentemente espacial da metáfora não consegue oferecer uma noção adequada do modo como a estrutura semiótica e os seus conteúdos se interpenetram, pois o ato de conter é compreendido não como físico ou espacial, mas como semiótico e significativo. $\mathrm{O}$ ato de conter é explicado por meio da comparação entre a tríade semiótica peirceana (signo-interpretante-objeto) e o que Wiley (1994) denomina "pentagrama impregnado de comunicação" (p.27) ou hexagrama. Embora a tríade semiótica seja abstrata, isto é, não exija necessariamente um remetente-destinatário ou emissor-interpretante, em situações concretas este par adicional estará presente, somando-se à tríade para formar um pentagrama ou hexagrama:

$$
\begin{gathered}
{\left[>_{1} \text { falante }^{6<}\left(>2 \text { Signo }->>_{3} \text { interpretante }->4 \text { objeto }\right)\right.} \\
\left.>5 \text { Ouvinte }{ }^{<5}\right]
\end{gathered}
$$

A maior parte da comunicação ocorre de forma linear $\left({ }^{>}\right)$, entre o remetente (falante ${ }_{1}$ ) e o destinatário (ouvinte ${ }_{5}$ ), como mostra a sequência numérica de ${ }_{1} \mathrm{a}_{5}$, no hexagrama indicado acima; porém uma parte dessa comunicação é reflexiva, ou seja, ocorre entre o remetente (falante ${ }^{6<}$ ) e ele mesmo. Essa característica reflexiva da comunicação acrescenta um sexto elemento ao esquema, tornando-o um hexagrama. $\mathrm{O}$ hexagrama contém a tríade do mesmo modo que a estrutura geral do self contém seu conteúdo. $\mathrm{O}$ ato de conter é funcional, mais do que espacial ou físico: é uma tríade dentro de uma tríade, onde o interno encontra-se subordinado ao externo (Wiley, 1994).

Tradução dos autores. O texto original é o seguinte: “A sign endeavors to represent, in part at least, an Object, which is therefore in a sense the cause, or determinant, of the sign even if the sign represents its object falsely. But to say that it represents its Object implies that it affects a mind, and so affects it as, in some respect, to determine in that mind something that is mediately due to the Object. That determination of which the immediate cause, or determinant, is the Sign, and of which the mediate cause is the Object may be termed the Interpretant" (CP. 6.347). ${ }^{2}$ Segue-se, neste estudo, a convenção de citar a Peirce pela grafia "CP. Números, sendo que o algarismo antes do ponto corresponde ao volume e depois do ponto ao parágrafo em The Collected papers of Charles S. Peirce (1958). 
Desta forma, afirma o autor, a definição peirciana 'o self é um signo' significa que o self é, estruturalmente, um signo; e o processo de conversação interna é, então, o self em funcionamento.

Além da tríade eu, mim, você, Wiley (1994) acrescenta outras três instâncias ou papéis à conversação interna: visitantes permanentes, visitantes temporários, e inconsciente. Os visitantes (tanto permanentes quanto temporários) recobrem todas as partes de "não-self" ou "outro". O conceito foi inspirado em um texto de Goethe de 1774, intitulado Os sofrimentos do jovem Werther. Era a história de um jovem enfermo e solitário que recebia mentalmente seus amigos no ambiente da conversação interna. Os hóspedes de Goethe ou os visitantes de Wiley são constituídos de pessoas próximas, com as quais se desfruta maior (permanentes) ou menor (temporários) convivência. A instância inconsciente recobre os estados não conscientes e os estados limítrofes, como devaneios ou fantasias da imaginação. Segundo o autor, ela foi incluída apenas como artifício para dramatizar o problema de localizála na conversação interna e não com a finalidade de trazer um entendimento acabado sobre o inconsciente. O perfil de cada instância é determinado a partir de outras cinco dimensões: pessoa (primeira, segunda ou terceira), tempo/conjugação (passado, presente, futuro, atemporal), caso (objetivo, subjetivo), liberdade/determinismo, relação com o outro generalizado (internalização das normas de uma sociedade), e disponibilidade cognitiva para o Eu. As dimensões de pessoa, tempo e caso são tomadas da linguística, mas apenas como metáforas para descrever as instâncias não linguísticas: "tendemos a descrever o self tanto com palavras quanto como palavras, mas isto não significa que as palavras sejam o self, ou que o self se reduza a palavras" (Wiley, 1994/1996, p. 73). ${ }^{3}$

O mim é definido como instância de primeira pessoa, pertencente à conjugação do passado. É objetivo, mas não é livre, e alia-se com o outro generalizado e disponível cognitivamente para o $\mathrm{Eu}$ como objeto. A instância Eu também pertence à primeira pessoa e à conjugação presente. É subjetivo, livre, sem vínculo com o outro generalizado, e constitui um ponto cego cognitivo para o próprio Eu.

3 Em geral cita-se a obra original em inglês de 1994. O principal problema da tradução de 1996 por Luiz Paulo Rouanet para as Edições Loyola foi tomar interpretant por intérprete, o que alterou completamente o usentido da tríade semiótica de Peirce. Assim, preferiu-se o neologismo correspondente, isto é, interpretante.
A instância você pertence à segunda pessoa e à conjugação do futuro, é subjetiva e objetiva, não livre e livre, e sua relação com o outro generalizado é de uma aliança menor e é disponível cognitivamente para o eu como sujeito.

Os visitantes temporários pertencem à segunda pessoa e à conjugação presente, são subjetivos e objetivos. Eles são mais livres que os visitantes permanentes e menos aliados ao outro generalizado que os visitantes permanentes. São disponíveis para o Eu como cossujeito. Os visitantes permanentes pertencem à segunda pessoa e à conjugação presente. Eles são objetivos e não livres, aliados e constitutivos do outro generalizado. São disponíveis para o Eu como cossujeito, mas sedimentados no outro generalizado. Por fim, o inconsciente é uma instância de terceira pessoa, atemporal, de todos os casos (objetivo, subjetivo, bem como objetivo e subjetivo, simultaneamente), determinado, livre da relação com o outro e está oculto do eu por barreiras lingüísticas semiporosas.

\section{CONVERGÊNCIAS E DIVERGÊNCIAS NAS PERSPECTIVAS SEMIÓTICA E DIALÓGICA DE SELF}

As perspectivas dialógica e semiótica de self concordam com relação à definição do self como um signo. A perspectiva semiótica afirma que o senso de self humano é um processo semiótico de autoprodução (Pickering, 1999, p. 70), por ser racional, simbólico e linguístico (Wiley, 1994). Este processo inclui sensações, emoções, pensamentos não linguísticos, hábitos, linguagem corporal e mesmo expressões irracionais ou subjetivas. Tomar o self como um signo significa entender, nos termos de Andacht e Michel (2005), que o self caracteriza-se como um processo de crescimento contínuo através de um diálogo reflexivo e interpretativo, constituindo a unidade de um processo generativo.

A noção de diálogo na perspectiva dialógica do self, resultante do esforço de traduzir a distinção de James entre Eu e Mim "em um arcabouço narrativo e no arcabouço conceitual do romance polifônico em particular" (Hermans \& Kempen, 1993, p. 44), também é semiótica. Contudo, a distinção de James entre Eu-Mim traduzida na distinção narrativa entre autor-ator, no tipo especial de relação sugerido por Bakhtin (1929/1973), aponta para uma semiótica diádica.

Na perspectiva semiótica, onde a conversação é tanto inter quanto intrapessoal e envolve uma circularidade reflexiva self-outro-self (ver Wiley, 
1994, p. 9-10), reformula-se a noção de diálogo em triálogo. A natureza humana é definida como uma estrutura horizontal, consistindo de fases temporais do self. O pragmatismo americano fornece a base para uma teoria do self tanto quanto ele o faz na perspectiva dialógica, porém, no lugar de uma distinção entre Eu e Mim de James, a perspectiva teórica semiótica descreve uma integração do eu-você de Peirce e do eu-mim de Mead. O resultado é um self complexo, definido como uma tríade de aspectos temporais chamados eu-você-mim e semioticamente mapeados como signo, interpretante e objeto (Wiley, 1994).

O signo e o interpretante estabelecem uma relação dialógica, na qual o objeto é discutido. O ponto de partida do self semiótico de Wiley é a direção temporal do diálogo interno nas teorias do self de ambos, Peirce e Mead. O self retrospectivo, representado na distinção eu (presente) - mim (passado) de Mead, é combinado com o self prospectivo representado na distinção eu (presente) você (futuro) de Peirce. Destarte, o self semiótico é a criação de sentido em uma estrutura temporal passado, presente e futuro - onde "tempo é um processo inerentemente de geração de sentido" (Wiley, 1994, p. 218). A maior preocupação, como afirma Pickering (1999, p. 67), parece ser retornar à "experiência humana de ser um self que persiste no tempo".

A natureza espacial do self, na teoria dialógica, é expressa nos termos posição e posicionamento. De acordo com os autores Hermans, Kempen e Van Loon (1992), estes termos são mais dinâmicos e flexíveis que o tradicional termo papel (role). O self é definido como uma multiplicidade de posições do Eu que dialogam entre si, mas em um espaço comum, onde a simultaneidade das vozes envolvidas no diálogo é a expressão da descentralização do self.

Neste sentido, a metáfora do romance polifônico assume uma função ontológica que traz as relações dialógicas para uma dimensão espacial, quando enfatiza a simultaneidade, a justaposição e a descontinuidade das vozes. Embora tempo e espaço sejam enfatizados como duas noções básicas e de igual importância na organização da narrativa, há, claramente, uma ênfase na dimensão espacial: o espaço é considerado como tão mais básico na medida em que o tempo é espacializado (Hermans \& Kempen, 1993). A espacialização do tempo é uma forma de responder à fraqueza das concepções tradicionais de narrativa e de autonarrativa, as quais são excessivamente pautadas por um viés temporal.
A ênfase no espaço e não no tempo levanta alguns problemas para a perspectiva dialógica de self. Conforme Barresi (2002), a noção de um eu autor que se multiplica em diversas vozes ou mim atores, simultâneos no tempo, implica a pressuposição de que um indivíduo pode adotar uma instância narrativa ou autoral, de alguma forma acima dos caracteres que formam o self polifônico e dialógico:

A fraqueza que eu vejo na formulação corrente da abordagem teórica de Hermans é a pressuposição de que um indivíduo pode adotar uma instância narrativa ou autoral, de alguma forma acima das personagens que compõem o self polifônico e dialógico, e pode mover a narrativa da posição do eu livremente, de uma personagem a outra, para dar a cada uma a sua própria voz. ${ }^{4}$ (p. 247)

Se o self pode assumir tal instância autoral, então a relação dialógica fica comprometida, uma vez que esse eu, acima dos outros caracteres, fica sozinho e sem interlocutores. Na concepção semiótica de self este problema é evitado, uma vez que a narrativa é sempre uma expressão comunicativa do eu, no tempo presente, em primeira pessoa.

A perspectiva dialógica de Hermans se diferencia da perspectiva pós-moderna, que entende o self como uma ilusão produzida ideologicamente a partir de uma fragmentação e pluralidade de identidades. Nesse sentido, o self dialógico está completamente em acordo com a posição de Wiley (1994) sobre o self semiótico: "eu vou criticar esta visão [de que o self é nada mais do que palavras comuns]" (p. 59).

Tanto o self semiótico quanto o self dialógico buscam um lugar intermediário entre racionalismo, empiricismo e idealismo para o self. Wiley (1994, p. 80) deixa clara tal posição ao definir sua noção de reflexividade, por ele entendida como "mais social que a versão de Descartes ou aquela dos empiricistas ingleses, mas menos social do que aquela dos idealistas alemães, o indivíduo sendo menos absorvido pela sociedade".

Hermans e Kempen (1993) seguem a mesma linha ao adotarem a noção jamesiana de self, que, embora colorida pela visão construcionista, não perde seu caráter pragmático de ênfase na relação entre o self e seu contexto. O modelo dialógico pressupõe que as diferentes vozes compartilham o presente temporal da mesma forma que a relação Eu-você peirciana, entendida na perspectiva de experiência coletiva de Schutz (1932/1967) (ver Wiley, 1994, p. 50). Isto é,

\footnotetext{
4 Tradução dos autores.
} 
quando Wiley focaliza o tempo presente das posições visitantes e o futuro do "você" (todas cognitivamente disponíveis para o eu como cossujeito), ele está recobrindo o mesmo fenômeno que Hermans ao descrever as diferentes vozes e posições que o "eu" pode assumir em um mesmo "tempo" presente.

A crítica à concepção de diálogo na teorização de Hermans (1996) se refere ao fato de que a definição de um self espacial, onde vozes copresentes dialogam, tende, inevitavelmente, à unidade ou à estabilidade monológica, nos termos de Grant (2004); isto é, o diálogo, ou a comunicação, ocorre em um espaço compartilhado ou comum - a esfera transcendental de diálogo, situada em algum lugar que neutraliza as diferenças de realidades de cada parte envolvida na interação comunicativa. Conforme o autor, a comunicação deve ser conceitualizada em termos da impenetrabilidade da mente do outro, isto é, as pretensões transcendentais devem ser abandonadas em favor de pretensões destranscendentalizadas. Quando Hermans (1996) define a noção de diálogo como interação entre atores mutuamente copresentes que tendem a um equilíbrio, a complexidade é reduzida à estabilidade. Para Grant (2004), a comunicação é complexa, portanto não pode ser traduzida em termos simples de interação (intersubjetividade) entre mentes, tampouco uma teoria do self pode explicar o self em termos de uma "sociedade da mente", como propõe Hermans (2002, p. 147): 'como uma sociedade, o self está baseado em dois princípios: troca intersubjetiva e dominação social (...)'. Para Grant (2004), o que marca a comunicação é a contingência e a complexidade e não a intersubjetividade. Seu argumento é contundente:

\begin{abstract}
Mesmo se alguém estivesse preparado para aceitar que o self realmente está interconectado, então não é com outras mentes, mas com outras vozes, no sentido proposto por Bakhtin (1989). E esta multiplicidade de vozes não deveria ser vista em termos de uma estabilidade normativa onde conflitos, falhas de comunicação e dissonância são resolvidos (p. 225).
\end{abstract}

Para Hermans, Kempen e Van Loon (1992), através do poder da imaginação, a pessoa pode agir como se fosse o outro, colocando o self espacialmente, tanto "aqui" como "lá". Mas isso - entendem os autores - não quer dizer o mesmo que tomar o papel do outro, nos termos de Mead (1934), na medida em que essa expressão implica que o self toma a perspectiva real do outro, fora do self. Ao invés disso, o eu constrói outra pessoa ou ser como uma posição que pode ocupar e uma posição que cria uma perspectiva alternativa sobre o mundo e sobre si mesmo.

\section{CONCLUSÃO}

As diferenças de ênfase na dimensão tempoespacial do self implicam em distinções igualmente importantes para a compreensão da noção de comunicação e de dialogicidade. A conversação interna é a base do self - entendido aqui como processo reflexivo da consciência - e funciona como uma relação dialógico-comunicativa que se estabelece no tempo. A dialogicidade é, portanto, a qualidade essencial desse processo, que é tanto interno ou reflexivo (a consciência voltando sobre si mesma) quanto externo ou flexivo (a consciência dirigindo-se a outras consciências). Nesse sentido, segue-se a linha de Morin (1993), que define como sinônimos os conceitos de fala interna, diálogo interno e fala consigo ou fala do self (self-talk); de Blachowicz (1997), quando argumenta que a fala interna é genuinamente um diálogo e não um monólogo; de Bertau (1999), ao sugerir que o pensamento verbalizado ou audível (índice mais aproximado que se pode obter da fala interna) funciona como um processo dialógico e de Bakhtin (1929/1973), que define as relações dialógicas como ato comunicativo.

As duas perspectivas trabalham com o signo, que é a percepção de sentido conversacional ou dialógica e a funcionalidade ou pragmática da expressão. A perspectiva dialógica volta-se à aplicabilidade do conceito recortando um contexto de pesquisa aplicada direcionada para a psicologia clínica e para as relações interpessoais; em contraste, a perspectiva semiótica volta-se para a funcionalidade do fenômeno, recortando um contexto de pesquisa inserido na psicologia dos processos básicos e da ética. Por conseguinte, a argumentação do self semiótico parece trazer uma fundamentação ontológica mais elegante. $\mathrm{O}$ conceito faz uma distinção entre a função evolucionária e a função cultural do self. A função evolucionária, comum a todos os seres humanos em todos os tempos e lugares, é a propriedade básica de geração de signos, sem a qual não haveria humanidade. Como gerador de signos, o self é uma estrutura, dialógica e anistórica. Como especificador de signos, o self é um conteúdo emergente ou sedimentado com matizes culturais e históricas.

Em contraste, a fundamentação ontológica do self dialógico é frágil, pois se apoia numa metáfora literária e romântica. Ao transformar o self em palco, tem que justificar a presença de um autor que fala por 
meio de atores. No entanto, a diferença entre autor e ator traz sérias dificuldades para sustentar a própria metáfora polifônica de simultaneidade, justaposição ou descontinuidade das posições, daí os problemas com as relações entre tempo e espaço. Por perder de vista as propriedades cognitivas humanas, o conceito de self dialógico recorre à imaginação para justificar o poder narrativo, deixando de lado a propriedade básica da reflexão. Por conseguinte, fica sem saber como explicar as relações metacognitivas que aparecem na hierarquia conversacional entre as posições, isto é, a metaposição. Reconheça-se, contudo, que a teoria de Hermans e colegas tem sido exitosa em chamar a atenção dos estudiosos do self para a importância da dialogicidade, da conversação interna e da negociação intra e interpessoal.

De qualquer modo, as perspectivas dialógica e semiótica representam novas ferramentas empíricas e analíticas para o estudo das relações entre aspectos comunicantes e funcionais do self. As especificidades de cada abordagem podem ser entendidas como facetas complementares em uma compreensão mais abrangente do fenômeno self; contudo, embora tanto a perspectiva dialógica quanto a semiótica ofereçam diretrizes epistemológicas claras para a investigação do self como um fenômeno comunicativo, a realização de estudos empíricos é um requisito indispensável para o refinamento dos instrumentos e da teoria.

As abordagens do Self Semiótico e do Self Dialógico apresentam-se como dois recursos teóricos e empíricos atrativos para a exploração dos meandros das nossas deliberações pessoais e para o exame das nossas relações intrapessoais e interpessoais. São também recursos sugestivos para desenvolvimento de estudos em tomada de decisão e em efetividade psicoterapêutica. Um provocativo debate entre as duas abordagens pode ser encontrado no número inaugural do International Journal for Dialogical Science, publicado em 2006.

\section{REFERÊNCIAS}

Andacht, F., \& Michel, M. (2005). A Semiotic reflection on selfinterpretation and identity. Theory \& Psychology, 15, 51-75.

Bakhtin, M. (1973). Problems of Dostoevsky's poetics (R. W. Rotsel, Trad). Ann Arbor: Ardis (Original publicado em 1929).

Bakhtin, M. M. (1989). The dialogic imagination: Four essays (M. Holquist, Trans.). Austin: University of Texas Press (Original publicado em 1975).

Barresi, J. (2002). From 'the Thought is the Thinker' to 'the Voice is the Speaker'. Theory \& Psychology, 12, 237-250.

Bertau, M.-C. (1999). Spuren des Gesprachs in innerer Sprache. Versuch einer Analyse der dialogischen Anteile des lautes
Denkens. [Marcas da fala em conversação interna. Uma análise da arte dialógica do pensamento em voz alta] Zeitchrift für Sprache \& Kognition, 18(1/2), 4-19.

Blachowicz, J. (1997). The dialogue of the soul with itself. Journal of Consciousness Studies 4, 485-508.

Grant, C. B. (2004). Complex communication and the self at the edge. Theory \& Psychology, 14, 221-237.

Hermans, H. J. M. (1996). Voicing the self: From information processing to dialogical interchange. Psychological Bulletin, 119, 31-50.

Hermans, H. J. M. (1999). Dialogical thinking and self-innovation. Culture \& Psychology, 5, 67-87.

Hermans, H. J. M. (2001a). The dialogical self: toward a theory of personal and cultural positioning. Culture \& Psychology, 7, 243281.

Hermans, H. J. M. (2001b). The construction of a personal position repertoire: method and practice. Culture \& Psychology, 7, 323365.

Hermans, H. J. M. (2002). The dialogical self as a society of mind. Theory \& Psychology, 12, 147-160.

Hermans, H. J. M. (2003). The construction and reconstruction of a dialogical self. Journal of Constructivist Psychology, 16, 89-130.

Hermans, H. J. M., \& Kempen, H. J. G. (1993). The Dialogical Self: Meaning as Movement. San Diego: Academic Press.

Hermans, H. J. M., Kempen, H. J. G. \& Van Loon, R. J. P (1992). The Dialogical Self: beyond individualism and rationalism. American Psychologist, 47, 23-33.

James, W. (1990). The principles of psychology. Chicago: Encyclopaedia Britannica (Original publicado em 1890).

Kelly, G. A. (1955). The psychology of personal constructs. New York: Norton.

Mancuso, J. C., \& Sarbin, T. R. (1983). The self-narrative in the enactment of roles. In: T. R. Sarbin, \& K. Scheibe (Eds.). Studies in social identity (pp. 254-273). New York: Praeger.

Mead, G. H. (1934). Mind, self and society. Chicago: University of Chicago Press. Recuperado em 02 de agosto de 2001 em www.spartan.ac.brocku.ca/ lward/default.html

Morin, A. (1993). Self-talk and self-awareness: on the nature of the relation. The Journal of Mind and Behavior 14, 223-234.

Peirce, C. S. (1958). Collected Papers of C. S. Peirce. Vol. I-VIII, C. Hartshorne, P. Weiss \& A. Burks (Eds.). Cambridge, Mass: Harvard University Press.

Pickering, J. (1999). The self is a semiotic process. In S. Gallagher \& J. Shear (Eds.), Models fo self (pp. 63-79). Exeter, UK: Imprint Academic.

Sarbin, Th. R. (1986). The narrative as a root metaphor for psychology. In: Th. R. Sarbin (Ed.). Narrative psychology: The storied nature of human conduct (pp. 3-21). New York: Praeger.

Schutz, A. (1967), The phenomenology of the social world (G. Walsh \& F. Lehnert, Trans.) Evanston, IL: Northwestern University Press (Original publicado em 1932).

Souza M., \& Gomes, W. (2005). Aspectos históricos e contemporâneos na investigação do self. Memorandum, 5(9), 7890.

Vaihinger, H. (1935). The philosophy of "As if". London: Kegan Paul, Trench \& Trubner. 
Vico, G. (1999). A ciência nova (M. Lucchesi, Trad.) Rio de Janeiro: Record (Original publicado em 1744).

Recebido em 03/12/2007

Wiley, N. (1994). The semiotic self. Chicago: The Univ. Chicago

Aceito em 01/08/2008

Press. [Em português: Wiley, N (1996). O self semiótico (L. P.

Rouanet, Trad.). São Paulo: Edições Loyola.

Endereço para correspondência : William B. Gomes. Rua Couto de Magalhães, 1155/601; CEP 90540-131, Instituto de Psicologia, UFRGS; Rua Ramiro Barcelos 2600 s/ 123; CEP 90035-005 Porto Alegre-RS, Brasil.E-mail: gomesw@ufrgs.br 